\title{
Accuracy and safety of C2 pedicle or pars screw placement: a systematic review and meta-analysis
}

\author{
Parisa Azimi ${ }^{{ }^{*}}$, Taravat Yazdanian² ${ }^{*}$, Edward C. Benzel ${ }^{3}$, Hossein Nayeb Aghaei ${ }^{1}$, Shirzad Azhari ${ }^{1}$,
} Sohrab Sadeghi ${ }^{1}$ and Ali Montazeri ${ }^{4}$

\begin{abstract}
Study design: Systematic review and meta-analysis.

Aim: The purpose of this study was to compare the safety and accuracy of the $C 2$ pedicle versus $C 2$ pars screws placement and free-hand technique versus navigation for upper cervical fusion patients.

Methods: Databases searched included PubMed, Scopus, Web of Science, and Cochrane Library to identify all papers published up to April 2020 that have evaluated C2 pedicle/pars screws placement accuracy. Two authors individually screened the literature according to the inclusion and exclusion criteria. The accuracy rates associated with C2 pedicle/pars were extracted. The pooled accuracy rate estimated was performed by the CMA software. A funnel plot based on accuracy rate estimate was used to evaluate publication bias.
\end{abstract}

Results: From 1123 potentially relevant studies, 142 full-text publications were screened. We analyzed data from 79 studies involving 4431 patients with 6026 C2 pedicle or pars screw placement. We used the Newcastle-Ottawa Scale (NOS) to evaluate the quality of studies included in this review. Overall, funnel plot and Begg's test did not indicate obvious publication bias. The pooled analysis reveals that the accuracy rates were $93.8 \%$ for C2 pedicle screw free-hand, $93.7 \%$ for pars screw free-hand, $92.2 \%$ for navigated C2 pedicle screw, and $86.2 \%$ for navigated C2 pars screw (all, $P$ value $<0.001$ ). No statistically significant differences were observed between the accuracy of placement C2 pedicle versus C2 pars screws with the free-hand technique and the free-hand C2 pedicle group versus the navigated $C 2$ pedicle group (all, $P$ value $>0.05$ ).

Conclusion: Overall, there was no difference in the safety and accuracy between the free-hand and navigated techniques. Further well-conducted studies with detailed stratification are needed to complement our findings.

Keyword: Upper cervical, Fusion, C2 pedicle, C2 pars, Radiographic malposition, Accuracy rate, Free-hand, Navigation

\footnotetext{
* Correspondence: parisa.azimi@gmail.com; taravat.yazdanian@gmail.com

${ }^{1}$ Department of Neurosurgery, Shahid Beheshti University of Medical

Sciences, Arabi Ave, Daneshjoo Blvd, Velenjak, Tehran 19839-63113, Iran

${ }^{2}$ School of Medicine, Capital Medical University, Beijing, China

Full list of author information is available at the end of the article
}

(c) The Author(s). 2020 Open Access This article is licensed under a Creative Commons Attribution 4.0 International License, which permits use, sharing, adaptation, distribution and reproduction in any medium or format, as long as you give appropriate credit to the original author(s) and the source, provide a link to the Creative Commons licence, and indicate if changes were made. The images or other third party material in this article are included in the article's Creative Commons licence, unless indicated otherwise in a credit line to the material. If material is not included in the article's Creative Commons licence and your intended use is not permitted by statutory regulation or exceeds the permitted use, you will need to obtain permission directly from the copyright holder. To view a copy of this licence, visit http://creativecommons.org/licenses/by/4.0/ The Creative Commons Public Domain Dedication waiver (http://creativecommons.org/publicdomain/zero/1.0/) applies to the data made available in this article, unless otherwise stated in a credit line to the data. 


\section{Background}

Atlantoaxial instability or upper cervical spine instability is defined as excessive mobility as a result of either a bony or ligamentous abnormality [1]. Operative treatment of atlantoaxial instability is performed with a variety of fixation techniques. Spinous process wiring techniques were developed in 1910; laminar wiring techniques were developed in 1939; C1-2 laminar and modified posterior wiring technique were developed in 1991 [2]. These techniques did not provide sufficient biomechanical stability [2]. To address this matter, the C1C2 transarticular screw fixation technique was introduced in 1992 [3]. However, 22\% of cases were not appropriate candidates for transarticular screws because of an increased risk of vertebral artery injury [4]. Some more recently developed methods of $\mathrm{C} 1-\mathrm{C} 2$ fixation, $\mathrm{C} 1$ lateral mass screws combined with $\mathrm{C} 2$ pedicle/pars/laminar screws, have enhanced the stability of the upper cervical spine fixation techniques $[2,5]$. C2 pedicle screw placement was first described by Goel et al. in the 1980s [2].

An alternative to the prior mentioned techniques is the pars screw, sometimes referred to as an isthmus screw. C2 screw fixation techniques have been enhanced by the development of poly-axial screws and top-loading rods [2]. Researchers showed that C2 pars and pedicle screw utilization leads to high rates of arthrodesis [5, 6]. These techniques are also employed in the subaxial cervical spine [5]. C2 pedicle and pars screws require accurate placement to avoid injury to vital structures, such as the vertebral artery, spinal cord, and nerve roots $[2,5]$.

Overall, navigated and free-hand technique has been reported in detail elsewhere [7]. CT-based intraoperative navigation can be applied to determine a safe trajectory for $\mathrm{C} 2$ pedicle and pars screws placement but may be associated with increased time for image acquisition, increased radiation exposure to the patient, and possible registration inaccuracies. On the other hand, the freehand technique minimizes radiation exposure to the surgeon and patient [5].

No systematic reviews to date have compared the accuracy and safety of $\mathrm{C} 2$ pedicle and pars screws placed with the free-hand technique to the safety and accuracy of screws placed with the assistance of navigation. Therefore, the purposes of this systematic review and meta-analysis are (1) to assess C2 pedicle and pars screw placement accuracy and (2) to evaluate the difference in $\mathrm{C} 2$ pedicle and pars screw placement accuracy between free-hand and navigation techniques based on radiographic malposition.

\section{Methods}

\section{Search strategy}

The research strategy was designed around the PICO (Patient, Intervention, Comparison, and Outcome) question format. The present review was performed, based on the Preferred Reporting Items for Systematic Reviews and Meta-analyses (PRISMA) guidelines [8]. Electronic searches were performed using the Scopus, PubMed, Web of Science, and Cochrane Library databases up to April 2020. The literature involving all comparative studies were searched, containing the following search terms: "C2 pedicle," "C2 pars," "atlantoaxial instability," "upper cervical," "spine," "CT-based technique, " "navigated technique," "craniocervical," "freehand technique," "screws," "screws placement," "accuracy rate," and "safety."

\section{Inclusion and exclusion criteria}

All identified articles were systematically evaluated against the inclusion and exclusion criteria, independently reviewed by 2 authors, and disagreements were sent to third author for resolution. Any disagreement was resolved by discussion to reach a consensus. The inclusion criteria were as follows: studies presented accuracy rate in pedicle and/or pars $\mathrm{C} 2$ screw placement, based on either the free-hand or navigation techniques.

In recent years, different navigation systems such as fluoroscopic navigation, MR-based navigation [9], CTguided navigation, and $\mathrm{O}$-arm-based navigation have been developed for pedicle/pars screw placement guidance. In this study, all of these techniques were considered navigation systems. The free-hand technique is defined by the placement of $\mathrm{C} 2$ pedicle or pars screws without the use of any of the aforementioned navigation systems [7]. In addition, screw guide templates and accuracy of preoperative imaging in predicting of trajectory and size of screw were considered free-hand technique.

The exclusion criteria were as follows: (I) duplicate publications; (II) reviews, case reports, commentary, and letters; (III) studies not published in English; (IV) studies which C2 screw sample size $<15$; and (V) studies without available data regarding statistical techniques and lack of radiographic malposition reporting; (VI) studies with anterior cervical surgery; (VII) studies regarding cadavers; (VIII) anatomical and biomechanical studies; (IX) studies regarding without detailed information of C2; and $(\mathrm{X})$ studies without separate $\mathrm{C} 2$ pedicle and pars screw placement information.

\section{Data extraction}

Two authors independently extracted the data from all eligible studies. The following data was extracted using a structured data extraction form from full articles: the first author, year of publication, country, sample size, gender, age, number of patients in $\mathrm{C} 2$ pars group in free-hand and navigation approach, number of patients in $\mathrm{C} 2$ pedicle group in free-hand and navigation approach, accuracy classification for assessing $\mathrm{C} 2$ pedicle/ 
pars screw placement, and accuracy rate in four subgroups as pedicle, pars free-hand and pedicle, and pars navigation technique based on radiological malposition.

\section{Quality assessment}

Identified studies were exported to Endnote version 7, and duplicates were removed. Two independent reviewers performed a full-text quality review. Disagreement between the two reviewers was resolved via discussion and a third author if needed. The NOS [10] was applied to evaluate the quality and risk of bias in included studies. The NOS includes 3 categorical criteria with a maximum score of 9 points: "selection" which accounts a maximum of 4 points, "comparability" which accounts a maximum of 2 points, and "outcome" which accounts a maximum of 3 points. No studies were randomized controlled trials; hence, studies with 7-9 points could be identified as high quality, 5-6 points as moderate quality, and $0-4$ as poor quality. A summary of the procedure of quality assessment is presented in Table 1.

\section{Statistical analysis}

The raw data were entered into Microsoft Excel. Exact tests were calculated with SPSS. Only mean values were reported for the variables age at surgery and the number of patients; these variables were only semi quantitatively compared. In studies that did not report the age of $\mathrm{C} 2$

Table 1 Check list for quality assessment and scoring of studies based on NOS

Check list

Selection

1. Representativeness of the sample. Truly representative

or somewhat representative? (if yes, one star)

2. Sample size $\geq 40$ (if yes, one star)

3. How representative was the $\mathrm{C} 2$ pedicle group in comparison with C2 pars screw placement in upper cervical patients, and the accuracy rate assessment is satisfactory? (if yes, one star; no star if the patients were selected only in one group)

4. Ascertainment of the risk factors as surgical record: Were the risk

factors measured with valid and reliable instruments? (if yes, one star)

Comparability

The accuracy rate screw placement and any additional factors as age, gender, and accurate classification of radiological malposition in different outcome groups are comparable, based on the study design or analysis. Confounding factors are controlled. (if yes, two stars; one star was assigned if one any additional factors was not reported)

Outcome assessment

6. Ascertainment of the outcome: clearly defined outcome of accuracy rate (yes, two star for information ascertained by record accuracy rate based on classification of radiological malposition; one star if this information was not reported)

7. Appropriate statistical analysis: The statistical test used to analyze the accuracy rate is clearly described and appropriate for C2 pedicle or pars pedicle (if yes, one star; no star was assigned if the accuracy rate is reported overall) pedicle/pars screw group, the mean age was considered. In addition, in some of studies, the number of unreported cases was determined by dividing by two the number of the $\mathrm{C} 2$ pedicle/pars. Also, in some of studies, overall accuracy rates were considered for subgroups.

The meta-analysis was performed by using the Comprehensive Meta-Analysis version 2 (Biostat, Englewood, NJ). We assumed that the methodology of each study was unique, and the studies were heterogeneous. I-squared statistics were used to evaluate the heterogeneity of pooled accuracy rate estimates. If the I-squared value was $>50 \%$ and $P$ value $<0.05$, there was significant heterogeneity among the included studies, and a random effects model was applied to estimate the pooled results. Publication bias was estimated using Begg's funnel plot. A 2-tailed $P$ value of less than 0.05 was considered statistically significant for all analyses.

\section{Results}

\section{Descriptive statistics}

The literature search identified a total of 1320 articles. Figure 1 shows the flow diagram for the selection process for the systematic review. After removing 197 duplicated articles, 1123 remaining records were screened for title and abstract. Of those articles, 981 were excluded. Thus, 142 articles were assessed for eligibility by reading the full text. No randomized controlled trials were identified. Seventynine articles including 67 retrospective studies and 12 prospective studies were included for meta-analysis. The mean age of patients was $49.9 \pm 13.3$ years, and $57.4 \%$ of patients were male. A tabulated summary of the all studies are presented in Table $2[5,9,11-87]$.

\section{Assessing screw placement accuracy}

The accuracy of $\mathrm{C} 2$ pedicle/pars screws placement was determined with intraoperative/postoperative CT imaging. There are 12 reported types of classification for assessing accuracy of $\mathrm{C} 2$ screw placement. Most studies used the Gertzbein et al. classification [88]. A summary of classifications and studies that used them is provided in Table 3 [7, 19, 21, 40, 49, 79, 85, 88-93].

\section{Study characteristics and quality assessment}

The characteristics of each study are shown in Table 2 . Fifty-seven studies were conducted in Asian countries, 12 studies in North America, and 10 studies in Europe. Sixty-seven studies were retrospective, and 12 were prospective in design. Sample size ranged from 10 to 328 patients. The reported accuracy rate ranged from 65.2 to $100 \%$ for patients after cervical surgery. The NOS for each study can be found in Table 2 . All of the studies analyzed in this systematic review scored five or above, which is considered of moderate to high quality studies [10], and 52 of the studies were considered high-quality studies. 


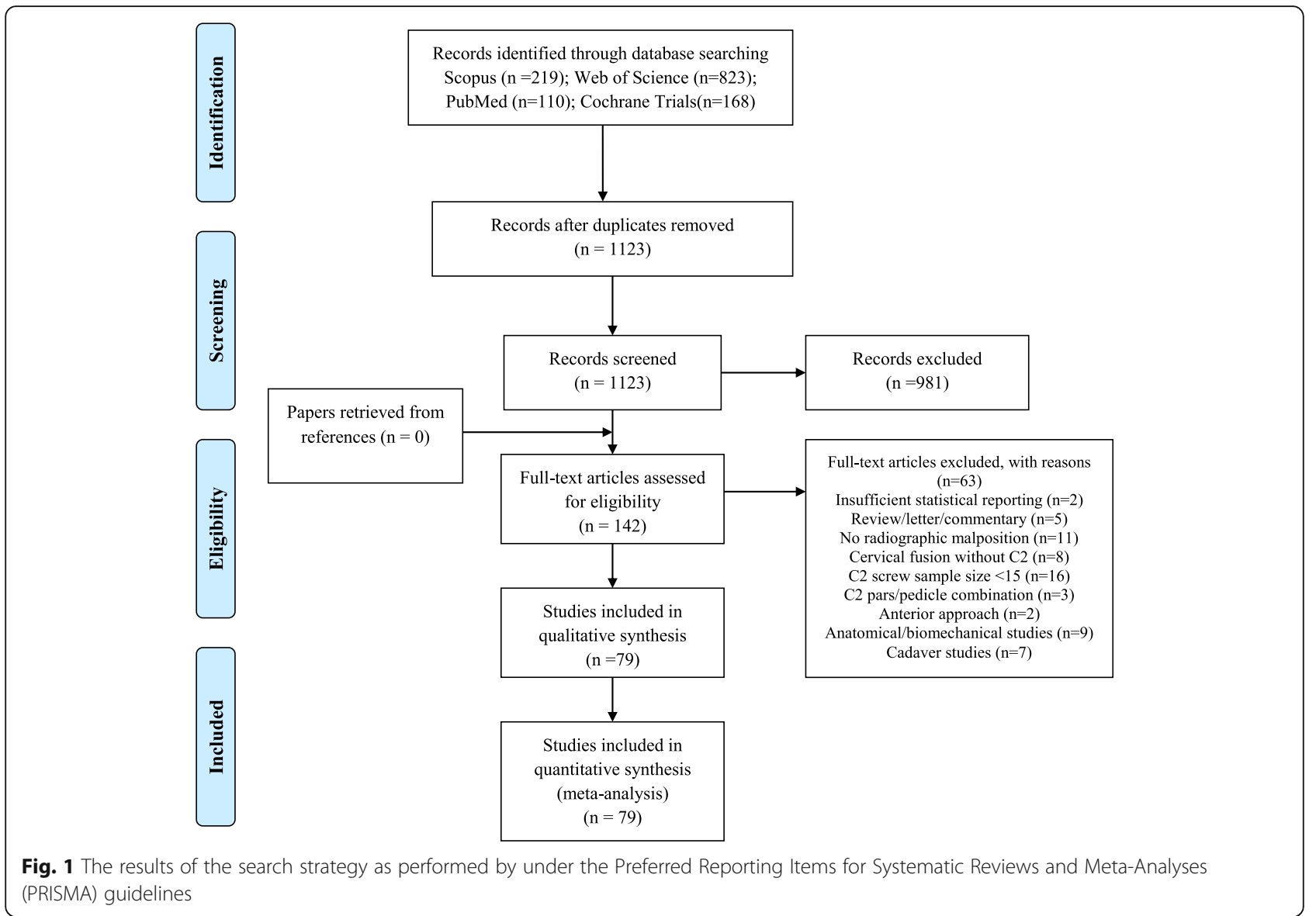

\section{Meta-analysis}

A total of 79 studies, comprising 4431 patients with upper cervical fusion, were included in the metaanalysis. Overall, $6026 \mathrm{C} 2$ pedicel/pars were used as follows: C2 pedicle free-hand $(n=4558)$, C2 pars free-hand $(n=506), \mathrm{C} 2$ pedicle navigation $(n=941)$, and C2 pars navigation $(n=21)$. There were 55 studies indicating the association between the pedicle screw placement and the accuracy rate of upper cervical fusion patients. Since there was significant heterogeneity among the above 55 studies (I-squared value $=79.8 \%$ and $P$ value $<0.001$ ), we performed a random effects model to assess the pooled accuracy rate estimate and corresponding 95\% CI. As shown in Fig. 2, the accuracy rate of the C2 pedicle screw free-hand technique was $93.8 \%$ ( $P$ value < 0.001 ). Forest plot for $C 2$ pars screw placement of freehand technique (15 studies, I-squared value $=0.0 \%$, and $P$ value $=0.599)$, C2 pedicle screw placement of navigation technique (22 studies, I-squared value $=21.63 \%$, and $P$ value $=0.178)$, and $C 2$ pars screw placement of navigation technique ( 2 studies, I-squared value $=0.0 \%$, and $P$ value $=0.608$ ) are shown in Fig. 3 (a fixed effects model; accuracy rate $93.7 \%$; $P$ value $<0.001$ ), Fig. 4 (a fixed effects model; accuracy rate $92.2 \% ; P$ value $<0.001$ ), and Fig. 5 (accuracy rate $86.2 \%$; $P$ value $<0.001$ ), respectively. In this systematic review study, no statistically significant results were observed between the accuracy of placement $\mathrm{C} 2$ pedicle versus $\mathrm{C} 2$ pars in free-hand technique and the free-hand $\mathrm{C} 2$ pedicle group versus the navigated $\mathrm{C} 2$ pedicle group (all, $P$ value $>0.05$ ).

\section{Publication bias}

Publication bias was measured by Begg's test. For C2 pedicle screw of free-hand technique, the $P$ value for Begg's test was 0.117, indicating that there was no significant publication bias among the included studies. Also, the $P$ value for Begg's test was 0.766 for the C2 pars screw free-hand technique. Funnel plot and Begg's test did indicate obvious published bias for $\mathrm{C} 2$ pedicle screw of navigation technique $(P=0.001)$. In addition, due to studies, less than 3 Begg's test was not performed for $\mathrm{C} 2$ pedicle screw of navigation technique.

\section{Discussion}

To our knowledge, no previous systematic review, with or without meta-analysis, has been reported with the same purpose and methods. The analysis of the literature reveals that there are many studies fulfilling the 
Azimi et al. Journal of Orthopaedic Surgery and Research

(2020) 15:272

Page 5 of 18

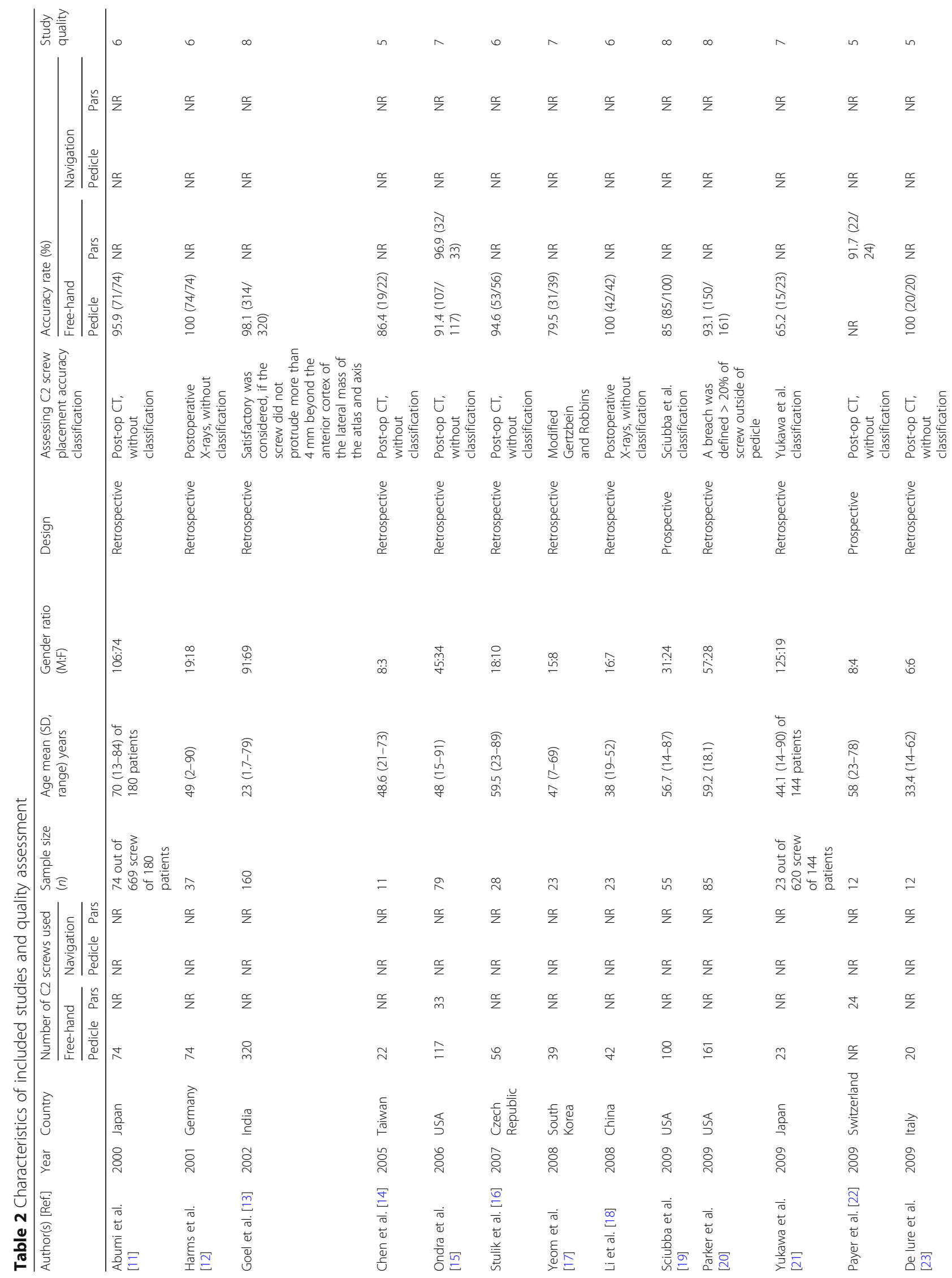




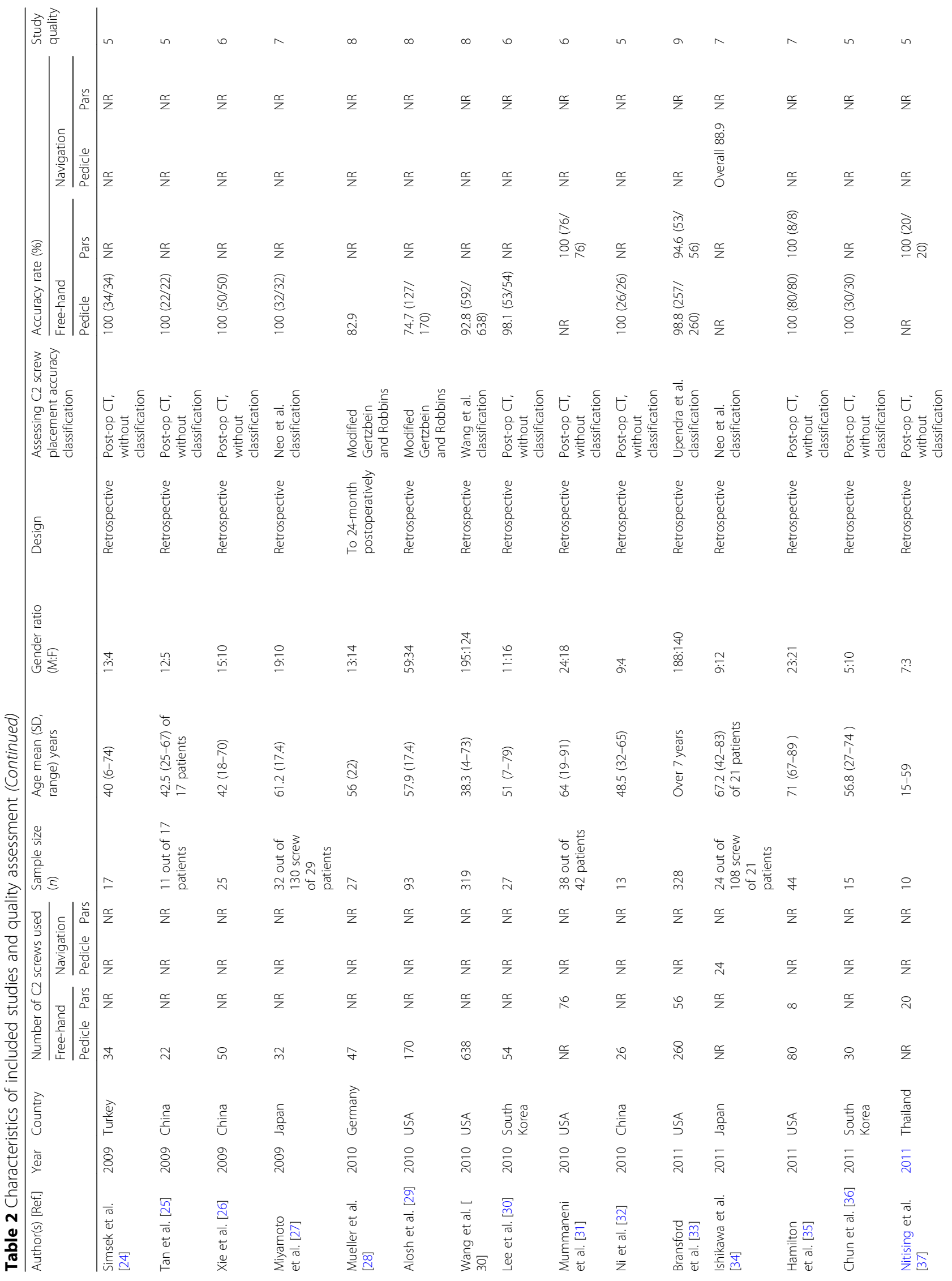




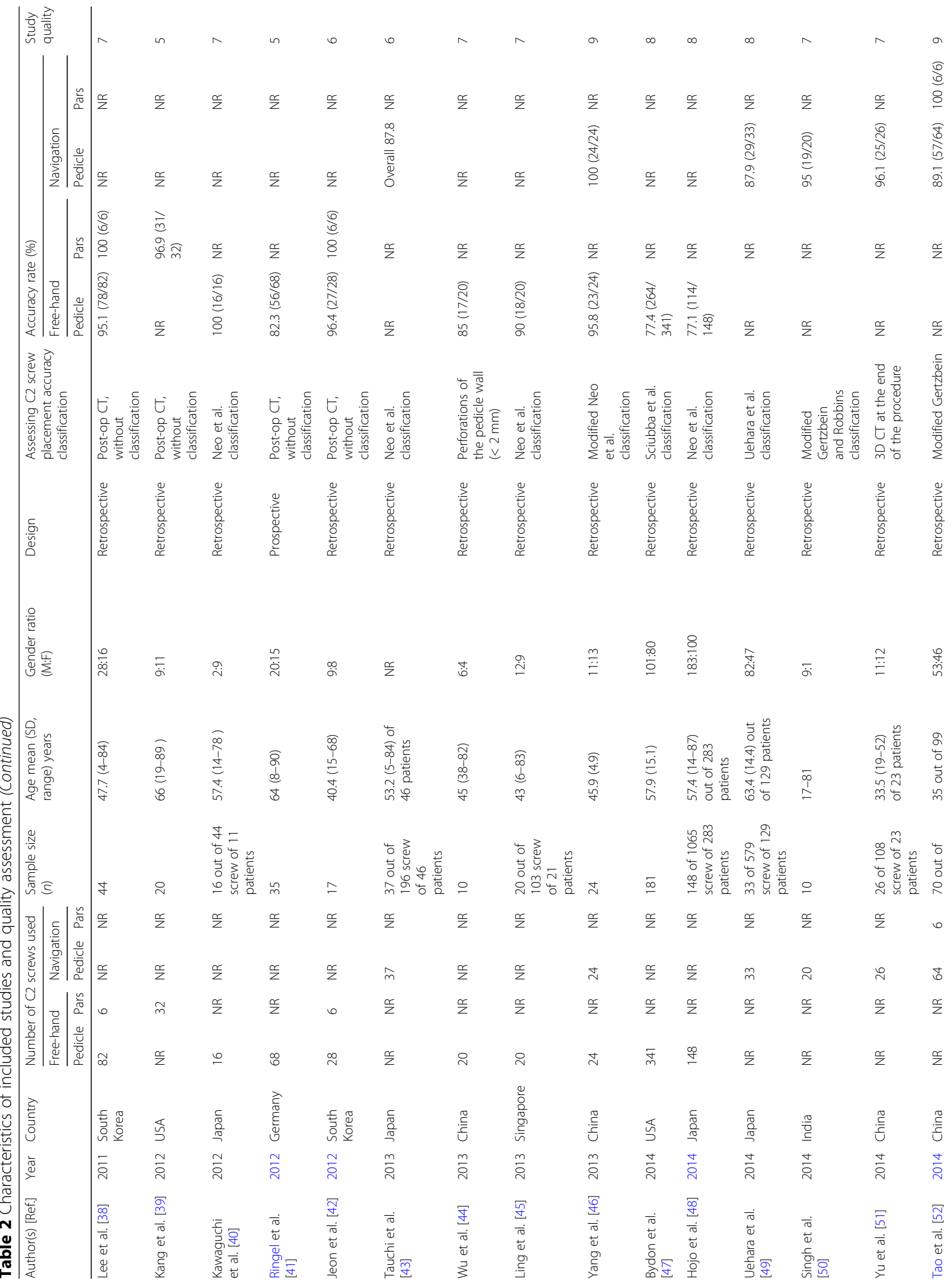




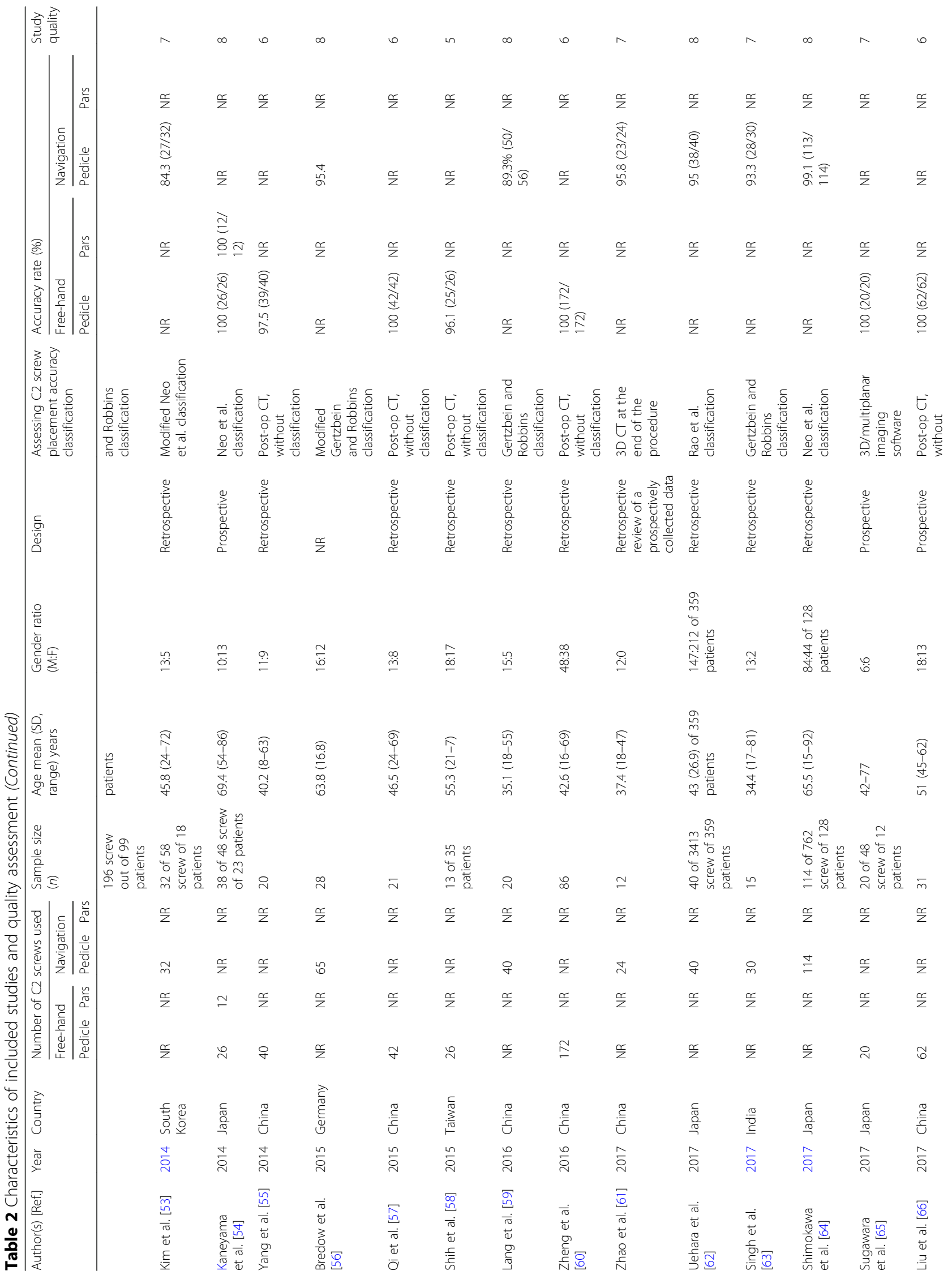




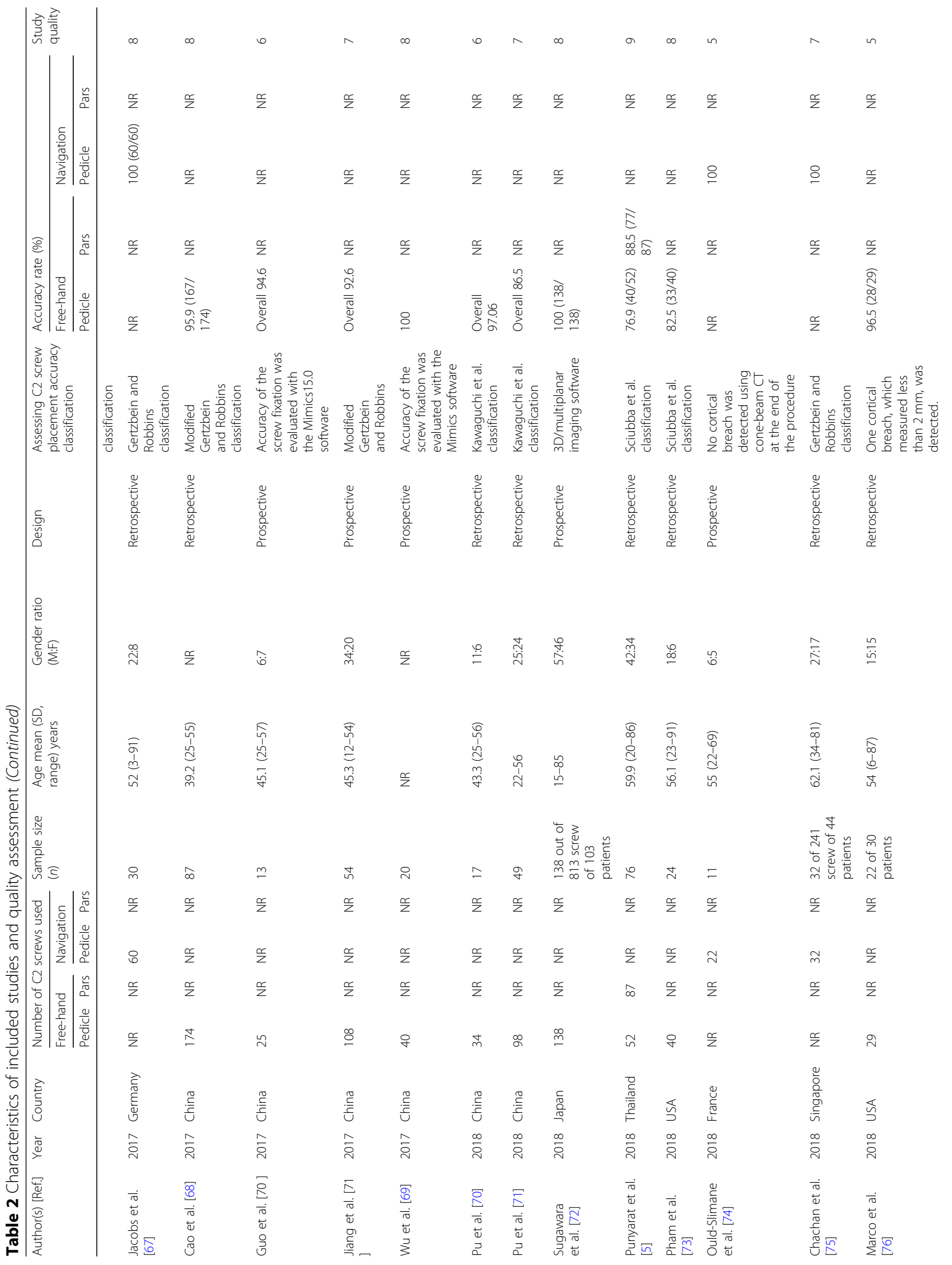




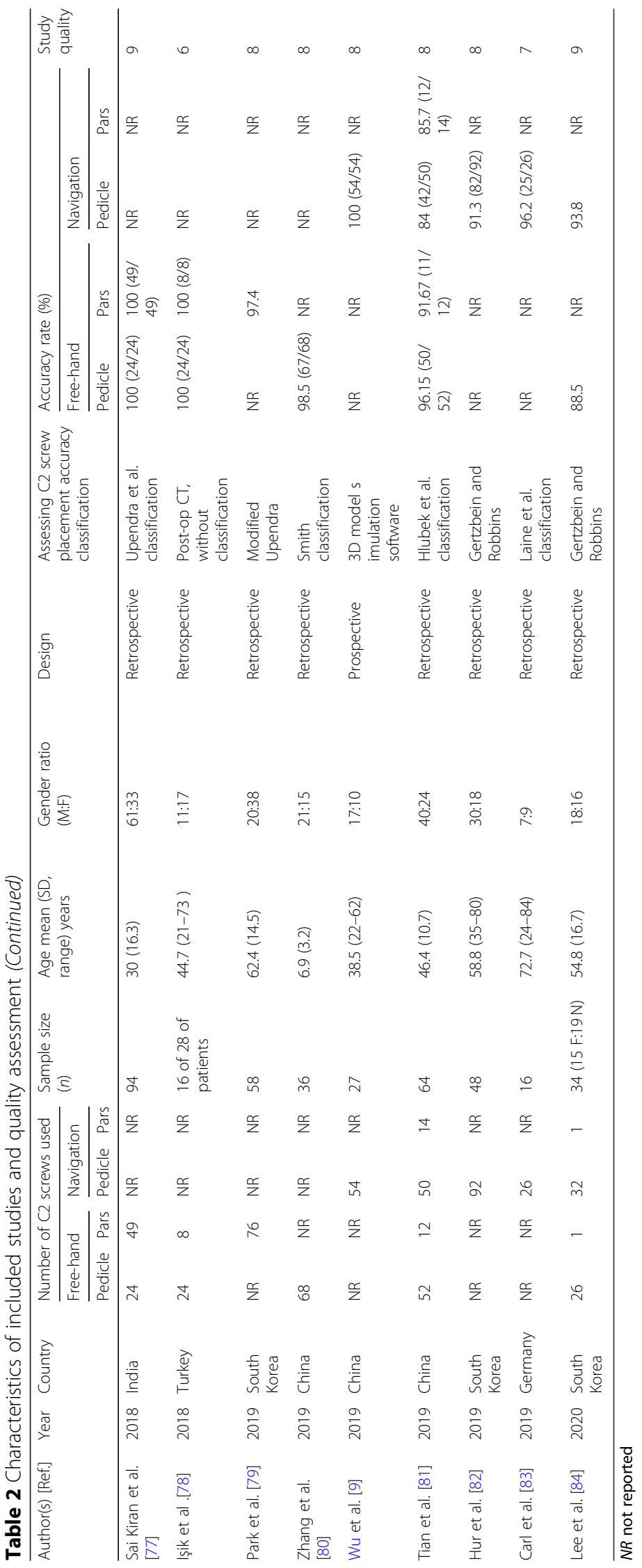


Table 3 Accuracy rate classifications for screw insertion

\begin{tabular}{|c|c|c|}
\hline Name of classification & Year & Description \\
\hline $\begin{array}{l}\text { Gertzbein and } \\
\text { Robbins [88] }\end{array}$ & 1990 & $\begin{array}{l}\text { Grade } 0 \text {, when a screw was placed inside the bone; grade I, screw } \\
\text { perforation of the cortex within } 2 \mathrm{~mm} \text {; grade II, screw perforation } \\
\text { from } 2 \text { to } 4 \mathrm{~mm} \text {; and grade III, screw perforation of more than } 4 \mathrm{~mm} \\
\text { In some of articles, this classification was modified [28, 56]. Grade } 0 \\
\text { is considered the accuracy of in C2 screw placement [28]. }\end{array}$ \\
\hline Laine et al. [89] & 2000 & $\begin{array}{l}\text { Based on CT images, in this classification, screw position was staged } \\
\text { as screw inside the pedicle or perforation of the pedicle cortex by } \\
\text { up to } 2 \mathrm{~mm} \text {, from } 2 \text { to } 4 \mathrm{~mm} \text {, from } 4 \text { to } 6 \mathrm{~mm} \text {, or by more than } \\
6 \mathrm{~mm} \text {. Type I and type II were categorized as acceptable placement. }\end{array}$ \\
\hline
\end{tabular}

Rao et al. [90]

Neo et al. [91]

Upendra et al. [92]. It was modified by Park et al. [79]

Sciubba et al. [19]

Yukawa et al. [21]

Wang et al. [85]

Kawaguchi et al. [40]

Uehara et al. [49].

Smith et al. [93]
2002 Each screw position was assigned a grade from 0 to 3, as follows: grade 0 reflected no perforation of the pedicle; grade 1 indicated less than $2 \mathrm{~mm}$ of perforation of the pedicle; grade 2 represented $2-4 \mathrm{~mm}$ of perforation of the pedicle; and grade 3 reflected perforation greater than $4 \mathrm{~mm}$. Grades 2 and 3 insertions were judged to be major perforations. Overall, it is considered a perforation of less than $2 \mathrm{~mm}$ to be satisfactory.

2005 Screw positions were classified into four grades: grade 0, no perforation, and the screw was completely contained in the pedicle; grade 1, perforation $<2 \mathrm{~mm}$ (that is, less than half of the screw diameter); grade 2 , perforations $\geq 2 \mathrm{~mm}$ but $<4 \mathrm{~mm}$; and grade 3 , perforation $\geq 4 \mathrm{~mm}$ (complete perforation). The screw was classified as grade 0 be acceptable.

2008 Type I, ideal placement—screw threaded completely within bony cortex; type Ila, acceptable placement $-<50 \%$ of the diameter of the screw violating surrounding cortex and screw protrusion of $<1 \mathrm{~mm}$ from the anterior cortex for pedicle and pars screws; type IIb, relatively acceptable placement-screw violating $<33 \%$ of the diameter of the C2 transverse foramen (TF); type IIc, relatively unacceptable placement-screw violating $\geq 33 \%$ of the diameter of the C2 TF or $\geq 50 \%$ of diameter of screw violating surrounding cortex; type III, unacceptable placement-clear violation of TF or spinal canal; regardless of clinical neurovascular complications. Overall, types I, Ila, and IIb were categorized as acceptable placement and types IIc and III as unacceptable placement.

2009 It is described by location (lateral, medial, inferior, and superior) and percentage of screw diameter over cortical edge $(0=$ none; grade I = $<25 \%$ of screw diameter; grade $\mathrm{II}=26-50 \%$; grade $\mathrm{III}=51-75 \%$; and grade IV $=76-100 \%)$. Type 0 was categorized as acceptable placement.

2009 The accuracy of the placement of the pedicle screws into the medial/ lateral pedicle walls was evaluated on axial CT scans ( $2 \mathrm{~mm}$ slices), whereas superior/inferior pedicle wall screw location was examined on oblique radiographs. Incorrect screw placement was classified as either screw exposure or pedicle perforation. A screw was exposed if it broke the pedicle wall, but more than $50 \%$ of the screw diameter remained within the pedicle. A pedicle perforation occurred if a screw breached the pedicle wall, and more than $50 \%$ of the screw diameter was outside the pedicle.

2010 This classification was based on axial plane, para-sagittal plane, and coronal plane. The grading has been described elsewhere in detail [85].

2012 Grade 0, the screw was completely located in the vertebral pedicle; grade I, the screw penetrated the pedicle bone cortex $<2 \mathrm{~mm}$ without complications; grade II, the screw penetrated the pedicle bone cortex $>2 \mathrm{~mm}$ without complications; and grade III, complications related to screw placement occurred, such as nerve and vertebral artery injuries. Grade 0 was considered to be the correct location of pedicle screws and safe placement.

2014 The screw insertion status was classified as grade 1 (no perforation), indicating that the screw was accurately inserted in pedicle; grade 2 (minor perforation), indicating perforation of less than $50 \%$ of the screw diameter; and grade 3 (major perforation), indicating perforation of 50\% or more of the screw diameter. The screw was classified as grade 1 be acceptable.

2016 On postoperative CT scans, type I was defined as ideal placement without cortical violation; type II was an acceptable placement with less than half the diameter of the screw violating the surrounding cortex and less than $1 \mathrm{~mm}$ protrusion from the anterior cortex; and type III is an unacceptable placement with clear violation of the transverse foramen or spinal canal.
Studies used the

classification

$[17,28,29,50,52,56,59,63$,

$67,68,75,82,84,87]$

$[27,34,40,43,45,46,48,53,54$

$[33,77,79]$

$[5,19,47,73]$

$[70,71]$ 
Table 3 Accuracy rate classifications for screw insertion (Continued)

\begin{tabular}{|c|c|c|c|}
\hline Name of classification & Year & Description & $\begin{array}{l}\text { Studies used the } \\
\text { classification }\end{array}$ \\
\hline Hlubek et al. [7] & 2018 & $\begin{array}{l}\text { Grade A, screw completely confined within cortical surfaces; grade B, transverse } \\
\text { foramen violation with the screw obstructing } 1-25 \% \text { of the foramen; grade C, } \\
\text { transverse foramen violation with the screw obstructing } 26-50 \% \text { of the foramen; } \\
\text { grade D, transverse foramen violation with the screw obstructing } 51-75 \% \text { of the } \\
\text { foramen; grade E, transverse foramen violation with the screw obstructing } 76- \\
100 \% \text { of the foramen; grade } \mathrm{M} \text {, medial breach into the spinal canal. Grades A } \\
\text { and B were determined to be acceptable placement, and Grades C-E and M } \\
\text { were determined to be unacceptable. }\end{array}$ & [81] \\
\hline
\end{tabular}

\begin{tabular}{|c|c|c|c|c|c|c|c|c|c|c|}
\hline \multirow[t]{2}{*}{ Study name } & \multicolumn{5}{|c|}{ Statistics for each study } & \multicolumn{5}{|c|}{ Event rate and $95 \% \mathrm{Cl}$} \\
\hline & $\begin{array}{c}\text { Event } \\
\text { rate }\end{array}$ & $\begin{array}{c}\text { Lower } \\
\text { limit }\end{array}$ & $\begin{array}{c}\text { Upper } \\
\text { limit }\end{array}$ & $z$-Value & $\mathrm{p}$-Value & -1.00 & -0.50 & 0.00 & 0.50 & 1.00 \\
\hline Abumi et al. 2000 & 0.959 & 0.881 & 0.987 & 5.377 & 0.000 & & & & & \\
\hline Harms et al. 2001 & 0.993 & 0.902 & 1.000 & 3.527 & 0.000 & & & & & \\
\hline Goel et al. 2002 & 0.981 & 0.959 & 0.991 & 9.632 & 0.000 & & & & & \\
\hline Chen et al. 2005 & 0.864 & 0.652 & 0.956 & 2.973 & 0.003 & & & & & \\
\hline Ondra et al. 2006 & 0.914 & 0.848 & 0.953 & 7.168 & 0.000 & & & & & \\
\hline Stulik et al. 2007 & 0.946 & 0.846 & 0.982 & 4.843 & 0.000 & & & & & \\
\hline Yeom et al. 2008 & 0.795 & 0.641 & 0.894 & 3.417 & 0.001 & & & & & \\
\hline Li et al.2008 & 0.988 & 0.840 & 0.999 & 3.123 & 0.002 & & & & & \\
\hline Sciubba et al. 2009 & 0.850 & 0.766 & 0.908 & 6.194 & 0.000 & & & & & \\
\hline Parker et al. 2009 & 0.931 & 0.880 & 0.961 & 8.368 & 0.000 & & & & & \\
\hline Yukawa et al. 2009 & 0.652 & 0.443 & 0.815 & 1.434 & 0.151 & & & & & \\
\hline De lure et al. 2009 & 0.995 & 0.926 & 1.000 & 3.741 & 0.000 & & & & & \\
\hline Simsek et al.2009 & 0.986 & 0.809 & 0.999 & 2.973 & 0.003 & & & & & \\
\hline Tan et al.2009 & 0.978 & 0.732 & 0.999 & 2.662 & 0.008 & & & & & \\
\hline Xie et al.2009 & 0.990 & 0.862 & 0.999 & 3.247 & 0.001 & & & & & \\
\hline Miyamoto et al.2009 & 0.985 & 0.799 & 0.999 & 2.929 & 0.003 & & & & & \\
\hline Mueller et al.2010 & 0.829 & 0.694 & 0.912 & 4.075 & 0.000 & & & & & \\
\hline Alosh et al.2010 & 0.747 & 0.676 & 0.807 & 6.137 & 0.000 & & & & & \\
\hline Wang et al. 2010 & 0.928 & 0.905 & 0.946 & 16.691 & 0.000 & & & & & \\
\hline Lee et al. 2010 & 0.981 & 0.880 & 0.997 & 3.957 & 0.000 & & & & & \\
\hline Ni et al.2010 & 0.981 & 0.764 & 0.999 & 2.781 & 0.005 & & & & & \\
\hline Bransford et al. 2011 & 0.988 & 0.964 & 0.996 & 7.744 & 0.000 & & & & & \\
\hline Hamilton et al. 2011 & 0.994 & 0.909 & 1.000 & 3.582 & 0.000 & & & & & \\
\hline Chun et al. 2011 & 0.984 & 0.789 & 0.999 & 2.883 & 0.004 & & & & & \\
\hline Lee et al.2011 & 0.951 & 0.877 & 0.981 & 5.797 & 0.000 & & & & & \\
\hline Kawaguchi et al.2012 & 0.971 & 0.664 & 0.998 & 2.436 & 0.015 & & & & & \\
\hline Ringel et al.2012 & 0.823 & 0.714 & 0.897 & 4.837 & 0.000 & & & & & \\
\hline Jeon et al.2012 & 0.964 & 0.786 & 0.995 & 3.241 & 0.001 & & & & & \\
\hline Wu et al.2013 & 0.850 & 0.624 & 0.951 & 2.770 & 0.006 & & & & & \\
\hline Ling et al.2013 & 0.900 & 0.676 & 0.975 & 2.948 & 0.003 & & & & & \\
\hline Yang et al.2013 & 0.958 & 0.756 & 0.994 & 3.073 & 0.002 & & & & & \\
\hline Bydon et al. 2014 & 0.774 & 0.727 & 0.815 & 9.508 & 0.000 & & & & & \\
\hline Hojo et al.2014 & 0.771 & 0.696 & 0.832 & 6.206 & 0.000 & & & & & \\
\hline kaneyama et al. 2014 & 0.981 & 0.764 & 0.999 & 2.781 & 0.005 & & & & & \\
\hline Yang et al.2014 & 0.975 & 0.843 & 0.996 & 3.617 & 0.000 & & & & & \\
\hline Qi et al. 2015 & 0.988 & 0.840 & 0.999 & 3.123 & 0.002 & & & & & \\
\hline Shih et al.2015 & 0.961 & 0.772 & 0.994 & 3.163 & 0.002 & & & & & \\
\hline Zheng et al.2016 & 0.997 & 0.956 & 1.000 & 4.126 & 0.000 & & & & & \\
\hline Sugawara et al.2017 & 0.976 & 0.713 & 0.999 & 2.594 & 0.009 & & & & & \\
\hline Liu et al.2017 & 0.992 & 0.885 & 1.000 & 3.401 & 0.001 & & & & & \\
\hline Cao et al.2017 & 0.959 & 0.917 & 0.980 & 8.245 & 0.000 & & & & & \\
\hline Guo et al.2017 & 0.946 & 0.756 & 0.990 & 3.236 & 0.001 & & & & & \\
\hline Jiang et al. 2017 & 0.926 & 0.859 & 0.963 & 6.874 & 0.000 & & & & & \\
\hline Wu et al. 2017 & 0.988 & 0.833 & 0.999 & 3.088 & 0.002 & & & & & \\
\hline Pu et al. 2018 & 0.970 & 0.818 & 0.996 & 3.458 & 0.001 & & & & & \\
\hline Pu X et al. 2018 & 0.865 & 0.782 & 0.920 & 6.284 & 0.000 & & & & & \\
\hline Sugawara et al. 2018 & 0.996 & 0.945 & 1.000 & 3.970 & 0.000 & & & & & \\
\hline Punyarat et al.2018 & 0.769 & 0.636 & 0.864 & 3.655 & 0.000 & & & & & \\
\hline Pham et al. 2018 & 0.825 & 0.676 & 0.914 & 3.726 & 0.000 & & & & & \\
\hline Marco et al. 2018 & 0.965 & 0.792 & 0.995 & 3.283 & 0.001 & & & & & \\
\hline Sai Kiran et al.2018 & 0.980 & 0.749 & 0.999 & 2.724 & 0.006 & & & & & \\
\hline Isik et al.2018 & 0.980 & 0.749 & 0.999 & 2.724 & 0.006 & & & & & \\
\hline Zhang et al. 2019 & 0.985 & 0.903 & 0.998 & 4.194 & 0.000 & & & & & \\
\hline Tian et al.2019 & 0.962 & 0.859 & 0.991 & 4.455 & 0.000 & & & & & \\
\hline Lee et al.2020 & 0.885 & 0.698 & 0.963 & 3.320 & 0.001 & & & & & \\
\hline Point estimate & 0.938 & 0.917 & 0.953 & 17.182 & 0.000 & & & & & \\
\hline
\end{tabular}

Fig. 2 Point estimates with 95\% confidence intervals and forest plot of studies reporting on accuracy rates of fusion following posterior atlantoaxial fusions with C2 pedicle screw and free-hand technique 


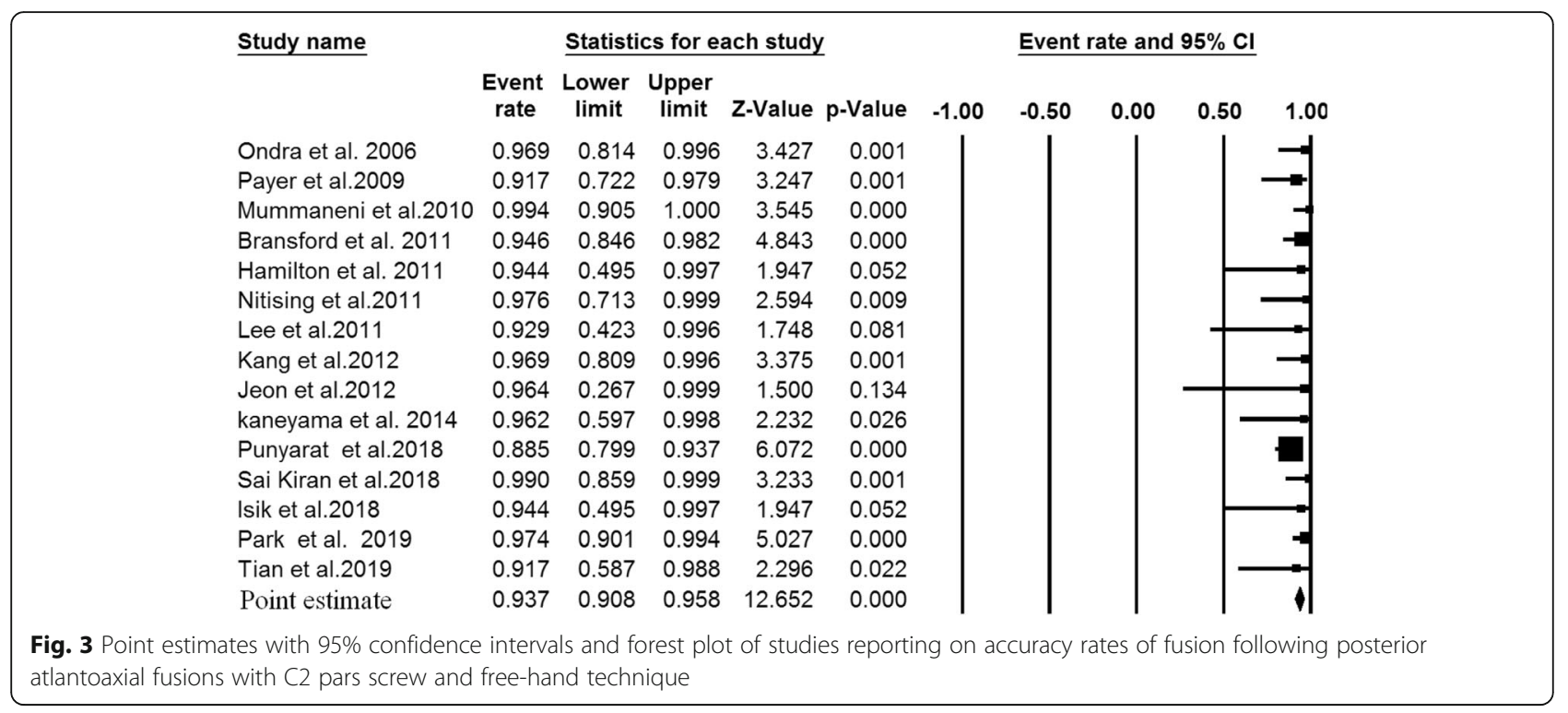

inclusion criteria of the present systematic review. That is why the current study can include 79 studies. Statistical analyses showed that the placement accuracy rate for the free-hand $\mathrm{C} 2$ pedicle group was comparable to that for the navigated $\mathrm{C} 2$ pedicle group and between $\mathrm{C} 2$ pedicle and pars screws placement. Overall, the freehand technique was not found to accurate than navigation for $\mathrm{C} 2$ pedicle/pars screw placement.

In this study, there was no difference in the safety and accuracy between the free-hand and navigated techniques, which could be for the following reasons: (a)
Screw guide template studies with the highest precision and accuracy were considered free-hand technique. (b) Experience with navigation system also plays a role in this arena. (c) Less number of navigation system studies compared to free-hand technique due to the lack of popular accessibility and (d) heterogeneity in studies.

\section{Study consistency}

Of the 79 articles, only 12 fully reported on patients' recruitment or the source of prospective data. No randomized trial was found. Learning curve and size of screws

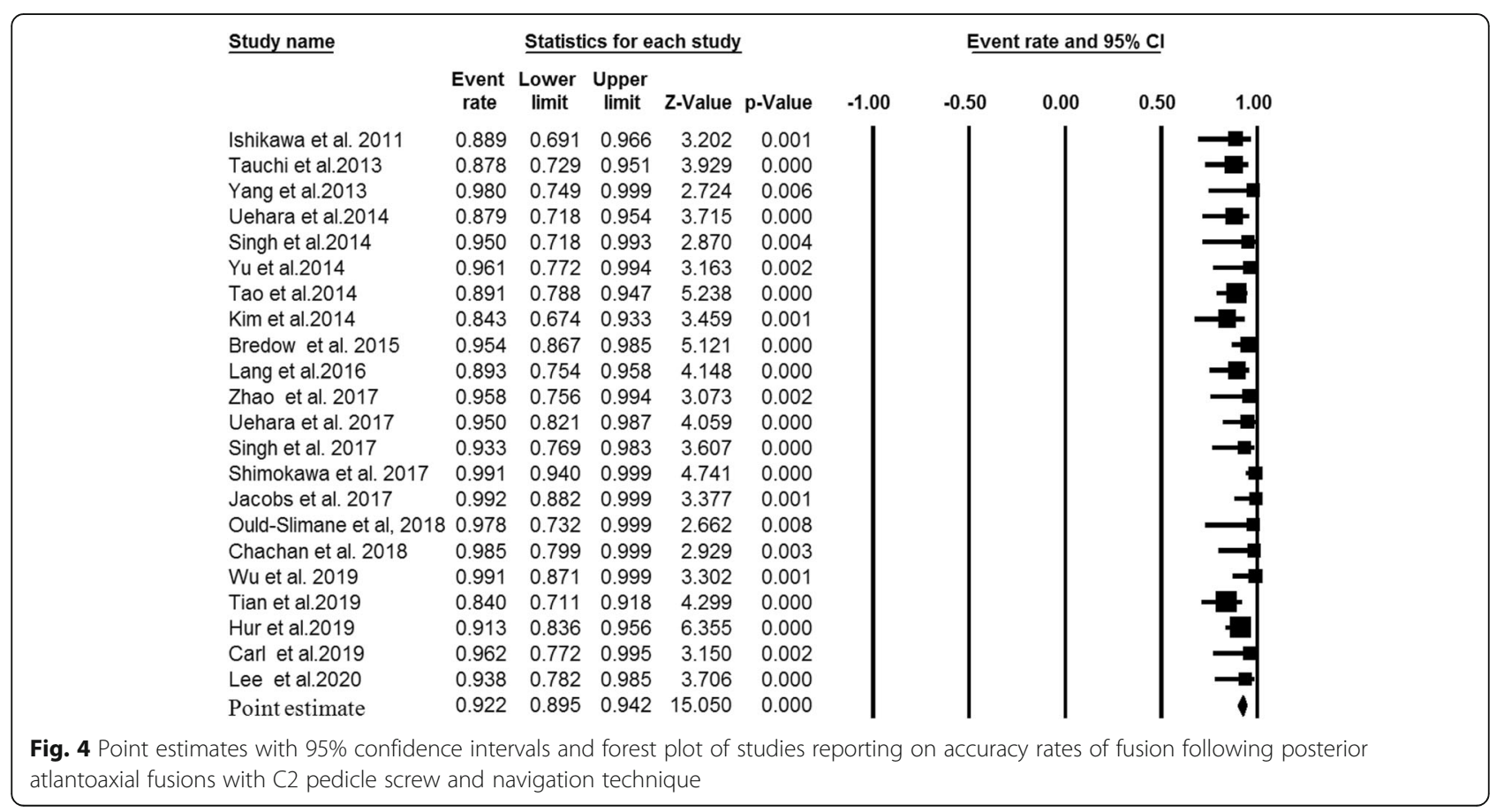




\begin{tabular}{|c|c|c|c|c|c|c|c|c|c|c|}
\hline \multirow[t]{2}{*}{ Study name } & \multicolumn{6}{|c|}{ Statistics for each study } & \multicolumn{4}{|c|}{ Event rate and $95 \% \mathrm{Cl}$} \\
\hline & $\begin{array}{c}\text { Event } \\
\text { rate }\end{array}$ & $\begin{array}{l}\text { Lower } \\
\text { limit }\end{array}$ & $\begin{array}{c}\text { Upper } \\
\text { limit }\end{array}$ & Z-Value & p-Value & -1.00 & -0.50 & 0.00 & 0.50 & 1.00 \\
\hline Tao et al. 2014 & 0.929 & 0.423 & 0.996 & 1.748 & 0.081 & & & & & \\
\hline Tian et al. 2019 & 0.857 & 0.749 & 0.923 & 5.015 & 0.000 & & & & & \\
\hline Point estimate & 0.862 & 0.760 & 0.925 & 5.286 & 0.000 & & & & & \\
\hline
\end{tabular}

Fig. 5 Point estimates with 95\% confidence intervals and forest plot of studies reporting on accuracy rates of fusion following posterior atlantoaxial fusions with C2 pars screw and navigation technique

were not consistently reported, resulting in a potential bias. The surgical approach was described in nearly all studies, while new entry point and trajectory, which could indicate a potential for screw malposition, were not consistently reported. For accuracy assessment of $\mathrm{C} 2$ pars/pedicle screw placement, a variety of grading criterion are reported in the literature. Comparison between accuracy rates was limited by the presence of twelve different definitions of accuracy rate and twenty-five studies $(31.6 \% ; 25 / 79)$ not presenting any definition. In addition, 14 articles $(17.7 \%$; 14/79) used the Gertzbein and Robbins grading system for evaluation of accuracy of screw placement. In a review study of $\mathrm{C} 2$ pedicle screw placement, Elliott et al. [94] showed that the incidence of malposition, confirmed by CT scan, varied from 1.1 to $44 \%$ in cases with fluoroscopic guidance. However, in this systematic review, the reported accuracy rate ranged from 65.2 to $100 \%$. This wide range could be a result of varying classification method of screw displacement among studies.

\section{Study quality}

Only 59.4\% (47/79) of studies used a clearly defined accuracy rate classification definition. Most studies were small with an average study group size of 44 patients dropping to 31 when removing the eight studies with over 100 patients. The method of screw insertion was well defined, or a pre-defined method was cited. In some of studies, the type and size of screws was not specified. Only two studies $[52,84]$ assessed the accuracy rate of navigated $\mathrm{C} 2$ pars screw malposition, and data were limited for comparison. Therefore, further research with large sample sizes comparing accuracy rates of navigation with free-hand methods is warranted.

Studies included heterogeneous populations with varying pathological types. However, accuracy of either procedure should not have been affected by pathology. Furthermore, more complex pathology or anatomy was not reason for choosing navigation over free-hand technique or vice versa [7]. Also, here was considerable regarding the length of $\mathrm{C} 2$ pars/pedicle screw, navigated technique, surgeon's experience, and grading criteria of accuracy, which can affect results. A standardized assessment process, moving forward, would greatly assist in future analyses in this arena. According to this 20-year study (2000-2020), over the past 20 years, numerous navigation systems such as MR-based navigation, CTguided navigation, and $\mathrm{O}$-arm-based navigation have been developed. Each of these systems has strengths and weaknesses concerning yield, cost, speed, and learning carve. Hence, it may cause heterogeneity to put all navigation systems in the same group. Albeit, it could be evaluated separately in the future.

Until now, a few studies have compared the accuracy of $\mathrm{C} 2$ pedicle and pars screw placement for atlantoaxial fusion [7, 84]. Lee et al. showed that O-arm navigation slightly improved the accuracy rate of $\mathrm{C} 2$ pedicle screw positioning, compared to the free-hand technique, though statistically meaningful results were not reported [84]. A C2 screw accuracy rate was reported to be $100 \%$ by Wu et al. [9]. They used 3D model simulation software for better evaluation of anatomy and then applied this to the navigation process [9]. Contrary to their study, Hlubek et al. found that the free-hand technique was significantly more accurate than CT-based navigation for $\mathrm{C} 2$ pedicle/pars screw placement [7]. Hence, illustrating the ongoing challenge associated with data analysis.

The corridor for $\mathrm{C} 2$ pedicle and pars screw placement is often narrow. Hence, it would seem that navigation techniques would present a natural solution to this corridor definition challenge in anatomically complex cases. There are several advantages of using an intraoperative image guidance for cervical surgery, including multi planar CT images of different operative levels in a single sequence can be achieved to increase accuracy of surgery, decreased radiation exposure to the surgeon and patient, and screw positions can be tested in the surgical field, which will reduce the failure rates [84]. On the other hand, surgical landmarks and fluoroscopy have been applied routinely for pedicle screw insertion, but a number of studies disclose inaccuracies in placement using these conventional techniques. Moreover, the free-hand technique is safe and accurate when it is in the hands of an experienced surgeon [95]. Then, it could be argued that the use of the navigation for $\mathrm{C} 2$ pars and pedicle placement is better than free-hand technique. However, there are many probable sources of error with the navigated 
method that resulted in less accurate screw placement. The CT image may be distorted because of metal artifacts from prior implant placement and the extra time required to set up the navigation system [84]. Also, the motion of $\mathrm{C} 2$ relative to the reference frame may introduce error. In addition, registration inaccuracies could be related to lack of correspondence between the pre-operative CT image, obtained in the standard supine position, and the intraoperative prone position, especially in patients with cervical instability. Other sources of inaccuracies include accidental displacement or reference frames [7]. Hence, in order to correct the source of error, further research is required to provide evidence of the precise cause of inaccuracy with navigated $\mathrm{C} 2$ pedicle and pars screw placement.

\section{Strengths and limitations}

The strengths of this review include the broad search strategy in four major databases and high sensitivity of the abstract search. This study has several limitations, though. First, this is a meta-analysis carried out at study level, meaning that different confounding factors from the patient level were not evaluated and included in the analysis. Second, the search was limited to English publications. Potentially relevant studies could have been missed. Third, although it seems that the CT-based navigation could be useful in $\mathrm{C} 2$ pedicle screw placement, this intraoperative CT navigation is not universally available. Moreover, it is mandatory to consider the radiation exposure for operative staff, which is significantly higher with CTbased navigated than with standard techniques. Fourth, all studies were performed retrospectively. To the best of our knowledge, no prior prospective randomized control studies have been performed to compare the safety and accuracy of the free-hand technique versus navigation for the placement of $\mathrm{C} 2$ pedicle and pars screws; hence, a high level of evidence was lacking in our review. Finally, the main limitation of the study was the high level of heterogeneity in the methods used among the included trials. In particular, there were heterogeneities in (1) variety in surgical technique and screw guide templates, (2) variety in navigation systems, (3) the screw placement accuracy measures applied, (4) length and size of screw (presently, there are no criteria on the size of $\mathrm{C} 2$ pedicle screws that maximizes the $\mathrm{C} 2$ accuracy rate placement), (5) the learning curve associated with using free-hand techniques and navigation systems, (6) costs from acquiring guidance technology, and (7) radiation exposure. These items were not discussed in the included articles, but it would be of interest in future prospective studies.

\section{Conclusion}

The C2 pedicle/pars placement accuracy rate for the free-hand group was comparable to that for the navigated group. Further randomized controlled trials with large sample sizes comparing accuracy rates of navigated with free-hand methods are warranted to complement the existing evidence.

\section{Abbreviations}

NOS: Newcastle-Ottawa Scale; CMA: Comprehensive Meta-Analysis Software

\section{Acknowledgements}

The authors thank the staff of the Neurosurgery Unit at Imam-Hossain Hospital, Tehran, Iran.

\section{Authors' contributions}

PA co-designed the study, conducted the searches, sorted the results, and was the major contributor in drafting the manuscript. TA and HNA COdesigned the study, assisted in interpretation of the data, and edited the manuscript. SA, SS, and ECB assisted in interpreting the data and editing the manuscript. PA and AM co-designed the study, contributed to interpretation of data, and were a major contributor in writing the manuscript. All authors read and approved the final manuscript.

Funding

None.

Availability of data and materials

Data sharing not applicable to this article as no datasets were generated. All datasets reviewed in this article are cited in the results section.

Ethics approval and consent to participate

Not applicable.

Consent for publication

Not applicable.

\section{Competing interests}

The authors declare that they have no competing interests.

\section{Author details}

${ }^{1}$ Department of Neurosurgery, Shahid Beheshti University of Medical Sciences, Arabi Ave, Daneshjoo Blvd, Velenjak, Tehran 19839-63113, Iran.

${ }^{2}$ School of Medicine, Capital Medical University, Beijing, China. ${ }^{3}$ Department of Neurosurgery, Cleveland Clinic Foundation, Cleveland, OH, USA.

${ }^{4}$ Population Health Research Group, Mental Health Research Group, Health Metrics Research Centre, Iranian Institute for Health Sciences Research, ACEC $R$, Tehran, Iran.

Received: 4 May 2020 Accepted: 14 July 2020

Published online: 20 July 2020

\section{References}

1. Savage JW, Limthongkul W, Park HS, Zhang L, Karaikovic EE. A comparison of biomechanical stability and pullout strength of two C1-C2 fixation constructs. Spine J. 2011;11(7):654-8.

2. Mummaneni PV, Haid RW. Atlantoaxial fixation: overview of all techniques. Neurol India. 2005;53(4):408-15.

3. Jeanneret $B$, Magerl F. Primary posterior fusion C1/2 in odontoid fractures: indications, technique, and results of transarticular screw fixation. J Spinal Disord. 1992;5(4):464-75.

4. Mandel IM, Kambach BJ, Petersilge CA, Johnstone B, Yoo JU. Morphologic considerations of $C 2$ isthmus dimensions for the placement of transarticular screws. Spine. 2000;25(12):1542-7.

5. Punyarat P, Buchowski JM, Klawson BT, Peters C, Lertudomphonwanit T, Riew KD. Freehand technique for C2 pedicle and pars screw placement: is it safe? Spine J. 2018;18(7):1197-203. 
6. Wang S, Wang C, Wood KB, Yan M, Zhou H. Radiographic evaluation of the 40 technique for $\mathrm{C} 1$ lateral mass and C2 pedicle screw fixation in three hundred nineteen 41 cases. Spine. 2011;36(1):3-8.

7. Hlubek RJ, Bohl MA, Cole TS, Morgan CD, Xu DS, Chang SW, Turner JD, Kakarla UK. Safety and accuracy of freehand versus navigated C2 pars or pedicle screw placement. Spine J. 2018;18(8):1374-81.

8. Moher D, Liberati A, Tetzlaff J, Althman D. Preferred reporting items for systematic reviews and meta-analyses: the PRISMA statement. PLoS Med. 2009;6(7):e1000097.

9. Wu X, Liu R, Xu S, Yang C, Yang S, Shao Z, Li S, Ye Z. Feasibility of mixed reality-based intraoperative three-dimensional image-guided navigation for atlanto-axial pedicle screw placement. Proc Inst Mech Eng H. 2019;233(12): $1310-7$.

10. Wells G, Shea B, O'Connell D, Peterson J, Welch V, Losos M, Tugwell P. The Newcastle-Ottawa Scale (NOS) for assessing the quality of nonrandomized studies in meta-analyses. http://www.ohri.ca/programs/clinical_ epidemiology/nosgen.pdf. Accessed on April 18, 2020.

11. Abumi K, Shono Y, Ito M, Taneichi H, Kotani Y, Kaneda K. Complications of pedicle screw fixation in reconstructive surgery of the cervical spine. Spine (Phila Pa 1976). 2000;25(8):962-9.

12. Harms J, Melcher RP. Posterior C1-C2 fusion with polyaxial screw and rod fixation. Spine (Phila Pa 1976). 2001 Nov 15;26(22):2467-71.

13. Goel A, Desai Kl, Muzumdar DP. Atlantoaxial fixation using plate and screw method: a report of 160 treated patients. Neurosurgery. 2002;51:1351-7.

14. Chen JF, Wu CT, Lee SC, Lee ST. Posterior atlantoaxial transpedicular screw and plate fixation. Technical note J Neurosurg Spine. 2005;2(3):386-92.

15. Ondra SL, Marzouk S, Ganju A, Morrison T, Koski T. Safety and efficacy of C2 pedicle screws placed with anatomic and lateral C-arm guidance. Spine. 2006:31(9):E263-7.

16. Stulik J, Vyskocil T, Sebesta P, Kryl J. Atlantoaxial fixation using the polyaxia screw-rod system. Eur Spine J. 2007;16(4):479-84.

17. Yeom JS, Buchowski JM, Park KW, Chang BS, Lee CK, Riew KD. Undetected vertebral artery groove and foramen violations during C1 lateral mass and C2 pedicle screw placement. Spine (Phila Pa 1976). 2008;33(25):E942-9.

18. Li L, Zhou FH, Wang H, Cui SQ. Posterior fixation and fusion with atlas pedicle screw system for upper cervical diseases. Chin J Traumatol. 2008, 11(6):323-8

19. Sciubba DM, Noggle JC, Vellimana AK, Alosh H, McGirt MJ, Gokaslan ZL, Wolinsky JP. Radiographic and clinical evaluation of free-hand placement of C-2 pedicle screws. J Neurosurg Spine. 2009;11(1):15-22.

20. Parker SL, McGirt MJ, Garcés-Ambrossi GL, Mehta VA, Sciubba DM, Witham TF, Gokaslan ZL, Wolinksy JP. Translaminar versus pedicle screw fixation of C2: comparison of surgical morbidity and accuracy of 313 consecutive screws. Neurosurgery. 2009;64(5 Suppl 2):343-8 discussion 348-9.

21. Yukawa Y, Kato F, Ito K, Horie Y, Hida T, Nakashima H, et al. Placement and complications of cervical pedicle screws in 144 cervical trauma patients using pedicle axis view techniques by fluoroscope. Eur Spine J. 2009;18: 1293-9.

22. Payer M, Luzi M, Tessitore E. Posterior atlanto-axial fixation with polyaxial C1 lateral mass screws and C2 pars screws. Acta Neurochir. 2009;151(3):223-9 discussion 229.

23. De lure F, Donthineni R, Boriani S. Outcomes of C1 and C2 posterior screw fixation for upper cervical spine fusion. Eur Spine J. 2009 Jun;18(Suppl 1):26.

24. Simsek S, Yigitkanli K, Seckin H, Akyol C, Belen D, Bavbek M. Freehand C1 lateral mass screw fixation technique: our experience. Surg Neurol. 2009; 72(6):676-81.

25. Tan J, Li L, Sun G, Qian L, Yang M, Zeng C, Teng H, Jia L. C1 lateral mass-C2 pedicle screws and crosslink compression fixation for unstable atlas fracture. Spine (Phila Pa 1976). 2009;34(23):2505-9.

26. Xie Y, Li Z, Tang H, Li M, Guan Z. Posterior C1 lateral mass and C2 pedicle screw internal fixation for atlantoaxial instability. J Clin Neurosci. 2009;16(12): 1592-4.

27. Miyamoto H, Uno K. Cervical pedicle screw insertion using a computed tomography cutout technique. J Neurosurg Spine. 2009;11(6):681-7.

28. Mueller CA, Roesseler L, Podlogar M, Kovacs A, Kristof RA. Accuracy and complications of transpedicular C2 screw placement without the use of spinal navigation. Eur Spine J. 2010;19(5):809-14.

29. Alosh H, Parker SL, McGirt MJ, Gokaslan ZL, Witham TF, Bydon A, Wolinsky JP, Sciubba DM. Preoperative radiographic factors and surgeon experience are associated with cortical breach of C2 pedicle screws. J Spinal Disord Tech. 2010;23(1):9-14.

30. Lee SH, Kim ES, Sung JK, Park YM, Eoh W. Clinical and radiological comparison of treatment of atlantoaxial instability by posterior C1-C2 transarticular screw fixation or C1 lateral mass-C2 pedicle screw fixation. J Clin Neurosci. 2010;17(7):886-92.

31. Mummaneni PV, Lu DC, Dhall SS, Mummaneni VP, Chou D. C1 lateral mass fixation: a comparison of constructs. Neurosurgery. 2010;66(3 Suppl):153-60.

32. Ni B, Zhu Z, Zhou F, Guo Q, Yang J, Liu J, Wang F. Bilateral C1 laminar hooks combined with $\mathrm{C} 2$ pedicle screws fixation for treatment of C1-C2 instability not suitable for placement of transarticular screws. Eur Spine J. 2010;19:1378-82.

33. Bransford RJ, Russo AJ, Freeborn M, Nguyen QT, Lee MJ, Chapman JR, Bellabarba C. Posterior C2 instrumentation: accuracy and complications associated with four techniques. Spine. 2011 15;36(14):E936-E943.

34. Ishikawa Y, Kanemura T, Yoshida G, Matsumoto A, Ito Z, Tauchi R, Muramoto A, Ohno S, Nishimura Y. Intraoperative, fullrotation, three-dimensional image (O-arm)-based navigation system for cervical pedicle screw insertion. J Neurosurg Spine. 2011;15(5):472-8.

35. Hamilton DK, Smith JS, Sansur CA, Dumont AS, Shaffrey CI. C-2 neurectomy during atlantoaxial instrumented fusion in the elderly: patient satisfaction and surgical outcome. Clinical article J Neurosurg Spine. 2011;15(1):3-8.

36. Chun HJ, Bak KH. Targeting a safe entry point for $\mathrm{C} 2$ pedicle screw fixation in patients with atlantoaxial instability. J Korean Neurosurg Soc. 2011;49(6): $351-4$.

37. Nitising A, Jetjumnong C, Tisavipat N, Nantaaree S. Posterior C1-C2 fusion using $\mathrm{C} 1$ lateral mass and C2 pars screw with rod fixation: techniques and outcomes. J Med Assoc Thail. 2011;94(7):794-800.

38. Lee $\mathrm{KH}$, Kang DH, Lee $\mathrm{CH}$, Hwang SH, Park IS, Jung JM. Inferolateral entry point for $\mathrm{c} 2$ pedicle screw fixation in high cervical lesions. J Korean Neurosurg Soc. 2011;50(4):341-7.

39. Kang MM, Anderer EG, Elliott RE, Kalhorn SP, Frempong-Boadu A. C2 nerve root sectioning in posterior C1-2 instrumented fusions. World Neurosurg. 2012;78(1-2):170-7.

40. Kawaguchi Y, Nakano M, Yasuda T, Seki S, Hori T, Kimura T. Development of a new technique for pedicle screw and Magerl screw insertion using a 3dimensional image guide. Spine. 2012;37(23):1983-8.

41. Ringel F, Reinke A, Stüer C, Meyer B, Stoffel M. Posterior C1-2 fusion with C1 lateral mass and C2 isthmic screws: accuracy of screw position, alignment and patient outcome. Acta Neurochir. 2012:154(2):305-12.

42. Jeon SW, Jeong JH, Choi GH, Moon SM, Hwang HS, Choi SK. Clinical outcome of posterior fixation of the $\mathrm{C} 1$ lateral mass and C2 pedicle by polyaxial screw and rod. Clin Neurol Neurosurg. 2012;114(6):539-44.

43. Tauchi R, Imagama S, Sakai $Y$, Ito $Z$, Ando K, Muramoto A, Matsui H, Matsumoto T, Ishiguro N. The correlation between cervical range of motion and misplacement of cervical pedicle screws during cervical posterior spinal fixation surgery using a CT-based navigation system. Eur Spine J. 2013;22(7): 1504-8.

44. Wu YS, Lin Y, Zhang XL, Tian NF, Sun LJ, Xu HZ, Chi YL, Pan ZJ. Management of hangman's fracture with percutaneous transpedicular screw fixation. Eur Spine J. 2013;22(1):79-86.

45. Ling JM, Tiruchelvarayan R, Seow WT, Ng HB. Surgical treatment of adult and pediatric C1/C2 subluxation with intraoperative computed tomography guidance. Surg Neurol Int. 2013;4(Suppl 2):S109-17.

46. Yang YL, Zhou DS, He JL. Comparison of isocentric C-arm 3-dimensional navigation and conventional fluoroscopy for C1 lateral mass and C2 pedicle screw placement for atlantoaxial instability. J Spinal Disord Tech. 2013;26(3): 127-34.

47. Bydon M, Mathios D, Macki M, De la Garza-Ramos R, Aygun N, Sciubba DM, et al. Accuracy of C2 pedicle screw placement using the anatomic freehand technique. Clin Neurol Neurosurg. 2014;125:24-7.

48. Hojo Y, Ito M, Suda K, Oda I, Yoshimoto H, Abumi K. A multicenter study on accuracy and complications of freehand placement of cervical pedicle screws under lateral fluoroscopy in different pathological conditions: $\subset T$ based evaluation of more than 1,000 screws. Eur Spine J. 2014;23(10):216674.

49. Uehara M, Takahashi J, Ikegami S, Mukaiyama K, Kuraishi S, Shimizu M, Futatsugi T, Ogihara N, Hashidate H, Hirabayashi H, Kato H. Screw perforation features in 129 consecutive patients performed computerguided cervical pedicle screw insertion. Eur Spine J. 2014;23(10):2189-95. 
50. Singh PK, Garg K, Sawarkar D, Agarwal D, Satyarthee GD, Gupta D, Sinha S, Kale SS, Sharma BS. Computed tomography-guided C2 pedicle screw placement for treatment of unstable hangman fractures. Spine. 2014;39(18): E1058-65.

51. Yu X, Li L, Wang P, Yin Y, Bu B, Zhou D. Intraoperative computed tomography with an integrated navigation system in stabilization surgery for complex craniovertebral junction malformation. J Spinal Disord Tech. 2014;27(5):245-52.

52. Tao X, Tian W, Liu B, Li Q, Zhang G. Accuracy and complications of posterior C2 screw fixation using intraoperative three-dimensional fluoroscopy-based navigation. Chin Med J. 2014;127(14):2654-8.

53. Kim SU, Roh BI, Kim SJ, Kim SD. The clinical experience of computed tomographic-guided navigation system in C1-2 spine instrumentation surgery. J Korean Neurosurg Soc. 2014;56(4):330-3.

54. Kaneyama S, Sugawara T, Sumi M, Higashiyama N, Takabatake M, Mizoi K. A novel screw guiding method with a screw guide template system for posterior C-2 fixation: clinical article. J Neurosurg Spine. 2014;21(2):231-8.

55. Yang JC, Ma XY, Xia H, Wu ZH, Ai FZ, Zhang K, Yin QS. Clinical application of computer-aided design-rapid prototyping in C1-C2 operation techniques for complex atlantoaxial instability. J Spinal Disord Tech. 2014;27(4):E143-50.

56. Bredow J, Oppermann J, Kraus B, Schiller P, Schiffer G, Sobottke R, Eysel P, Koy T. The accuracy of 3D fluoroscopy-navigated screw insertion in the upper and subaxial cervical spine. Eur Spine J. 2015;24(12):2967-76.

57. Qi L, Li M, Zhang S, Si H, Xue J. C1-C2 pedicle screw fixation for treatment of old odontoid fractures. Orthopedics. 2015;38(2):94-100.

58. Shih YT, Kao TH, Pan HC, Chen HT, Tsou HK. The surgical treatment principles of atlantoaxial instability focusing on rheumatoid arthritis. Biomed Res Int. 2015;2015:518164.

59. Lang Z, Tian W, Liu Y, Liu B, Yuan Q, Sun Y. Minimally invasive pedicle screw fixation using intraoperative 3-dimensional fluoroscopy-based navigation (CAMISS Technique) for hangman fracture. Spine (Phila Pa 1976). 2016;41(1): 39-45.

60. Zheng Y, Hao D, Wang B, He B, Hu H, Zhang H. Clinical outcome of posterior C1-C2 pedicle screw fixation and fusion for atlantoaxial instability: a retrospective study of 86 patients. J Clin Neurosci. 2016;32:47-50.

61. Zhao J, Xu P, Zhang S, Mu W. Treatment for odontoid fracture with C1 lateral mass and C2 pedicle screws using intraoperative orbic-3-dimensional navigation. Int J Clin Exp Med. 2017:10(9):14150-8.

62. Uehara M, Takahashi J, Ikegami S, Kuraishi S, Futatsugi T, Kato H. Screw perforation rates in 359 consecutive patients receiving computer-guided pedicle screw insertion along the cervical to lumbar spine. Eur Spine J. 2017;26(11):2858-64.

63. Singh PK, Verma SK, Garg M, Sawarkar DP, Kumar A, Agrawal D, Chandra SP, Kale SS, Sharma BS, Mahapatra AK. Evaluation of correction of radiologic parameters (angulation and displacement) and accuracy of C2 pedicle screw placement in unstable hangman's fracture with intraoperative computed tomography-based navigation. World Neurosurg. 2017;107:795802.

64. Shimokawa N, Takami T. Surgical safety of cervical pedicle screw placement with computer navigation system. Neurosurg Rev. 2017;40(2):251-8.

65. Sugawara T, Higashiyama N, Kaneyama S, Sumi M. Accurate and simple screw insertion procedure with patient-specific screw guide templates for posterior C1-C2 fixation. Spine. 2017;42(6):E340-6.

66. Liu JM, Jiang J, Liu ZL, Long XH, Chen WZ, Zhou Y, Gao S, He LC, Huang SH. A new entrance technique for $\mathrm{C} 2$ pedicle screw placement and the use in patients with atlantoaxial instability. Clin Spine Surg. 2017;30(5):E573-7.

67. Jacobs C, Roessler PP, Scheidt S, Plöger MM, Jacobs C, Disch AC, Schaser $K D$, Hartwig T. When does intraoperative 3D-imaging play a role in transpedicular C2 screw placement? Injury. 2017;48(11):2522-8.

68. Cao L, Yang E, Xu J, Lian X, Cai B, Liu X, Zhang G. "Direct vision" operation of posterior atlantoaxial transpedicular screw fixation for unstable atlantoaxial fractures: a retrospective study. Medicine (Baltimore). 2017 Jun; 96(25):e7054.

69. Wu X, Liu R, Yu J, Lu L, Yang C, Shao Z, Ye Z. Deviation analysis for C1/2 pedicle screw placement using a three-dimensional printed drilling guide. Proc Inst Mech Eng H. 2017 Jun;231(6):547-54.

70. Pu X, Luo C, Lu T, Yao S, Chen Q. Clinical application of atlantoaxial pedicle screw placement assisted by a modified 3D-printed navigation template. Clinics (Sao Paulo). 2018 Jul 19;73:e259.

71. Pu X, Yin M, Ma J, Liu Y, Chen G, Huang Q, Zhao G, Lu T, Yao S, Chen Q, Luo $C$. Design and application of a novel patient-specific three-dimensional printed drill navigational guiding in atlantoaxial pedicle screw placement. World Neurosurg. 2018;114:e1-e10.

72. Sugawara T, Kaneyama S, Higashiyama N, Tamura S, Endo T, Takabatake M, Sumi M. Prospective multicenter study of a multistep screw insertion technique using patient-specific screw guide templates for the cervical and thoracic spine. Spine (Phila Pa 1976). 2018;43(23):1685-94.

73. Pham MH, Bakhsheshian J, Reid PC, Buchanan IA, Fredrickson VL, Liu JC. Title: Evaluation of $C 2$ pedicle screw placement via the freehand technique by neurosurgical trainees. J Neurosurg Spine. 2018;29(3):235-40.

74. Ould-Slimane M, Ferracci FX, Le Pape S, Perez A, Michelin P, Gauthé R. Posterior C1C2 harms fusion with 3D surgical navigation. Orthop Traumatol Surg Res. 2018;104(5):585-8.

75. Chachan S, Bin AbdRazak HR, Loo WL, Allen JC, Shree KD. Cervical pedicle screw instrumentation is more reliable with $\mathrm{O}$-arm-based 3D navigation: analysis of cervical pedicle screw placement accuracy with O-arm-based 3D navigation. Eur Spine J. 2018;27(11):2729-36

76. Marco RAW, Phelps Cl, Kuo RC, Zhuge WU, Howard CW, Kushwaha VP, Bernstein DT. Radiologic analysis of C2 to predict safe placement of pedicle screws. Int J Spine Surg. 2018;12(1):30-6.

77. Sai Kiran NA, Sivaraju L, Vidyasagar K, Aryan S, Raj V, Rajagopal N, Mohan D, Thakar S, Rao AS, Hegde AS. Safety and accuracy of anatomic and lateral fluoroscopic-guided placement of C2 pars/pedicle screws and C1 lateral mass screws, and freehand placement of C2 laminar screws. World Neurosurg. 2018;118:e304-15.

78. Işik HS, Sandal E, Çağli S. Clinical outcomes of posterior C1 and C2 screwrod fixation for atlantoaxial instability. Turk Neurosurg. 2018;28(4):602-9.

79. Park JH, Lee JB, Lee HJ, Kim IS, Hong JT. Accuracy evaluation of placements of three different alternative C2 screws using the freehand technique in patients with high riding vertebral artery. Medicine (Baltimore). 2019;98(46): e17891.

80. Zhang YH, Zhou FC, Zhang J, Song J, Shao J. Efficacy and safety of atlantoaxial fluoroscopy-guided pedicle screw fixation in patients younger than 12 years: a radiographic and clinical assessment. Spine. 2019;44(20): $1412-7$.

81. Tian Y, Zhang J, Liu T, Tang S, Chen H, Ding K, Hao D. A comparative study of C2 pedicle or pars screw placement with assistance from a 3-dimensiona (3D)-printed navigation template versus C-arm based navigation. Med Sci Monit. 2019;25:9981-90.

82. Hur JW, Kim JS, Ryu KS, Shin MH. Accuracy and safety in screw placement in the high cervical spine: retrospective analysis of O-arm-based navigationassisted C1 lateral mass and C2 pedicle screws. Clin Spine Surg. 2019;32(4): E193-9.

83. Carl B, Bopp M, Pojskic M, Voellger B, Nimsky C. Standard navigation versus intraoperative computed tomography navigation in upper cervical spine trauma. Int J CARS. 2019:14(1):169-82.

84. Lee JS, Son DW, Lee SH, Ki SS, Lee SW, Song GS. Comparative analysis of surgical outcomes of C1-2 fusion spine surgery between intraoperative computed tomography image based navigation-guided operation and fluoroscopy-guided operation. J Korean Neurosurg Soc. 2020;63(2):237-47.

85. Wang S, Wang C, Wood KB, Yan M, Zhou H. Radiographic evaluation of the technique for $\mathrm{C} 1$ lateral mass and $\mathrm{C} 2$ pedicle screw fixation in three hundred nineteen cases. Spine. 2010;36(1):3-8

86. Guo F, Dai J, Zhang J, Ma Y, Zhu G, et al. Individualized 3D printing navigation template for pedicle screw fixation in upper cervical spine. PLoS One. 2017;12(2):e0171509.

87. Jiang L, Dong L, Tan M, Qi Y, Yang F, Yi P, Tang X. A Modified personalized image-based drill guide template for atlantoaxial pedicle screw placement: a clinical study. Med Sci Monit. 2017;23:1325-33.

88. Gertzbein SD, Robbins SE. Accuracy of pedicular screw placement in vivo. Spine (Phila Pa 1976). 1990;15(1):11-4

89. Laine T, Lund T, Ylikoski M, Lohikoski J, Schlenzka D. Accuracy of pedicle screw insertion with and without computer assistance: a randomised controlled clinical study in 100 consecutive patients. Eur Spine J. 2000;9(3): 235-40.

90. Rao G, Brodke DS, Rondina M, Dailey AT. Comparison of computerized tomography and direct visualization in thoracic pedicle screw placement. J Neurosurg. 2002;97(2 Suppl):223-6.

91. Neo M, Sakamoto T, Fujibayashi S, Nakamura T. The clinical risk of vertebral artery injury from cervical pedicle screws inserted in degenerative vertebrae. Spine (Phila Pa 1976). 2005:30(24):2800-5. 
92. Upendra BN, Meena D, Chowdhury B, Ahmad A, Jayaswal A. Outcomebased classification for assessment of thoracic pedicular screw placement Spine (Phila Pa 1976). 2008;33(4):384-90.

93. Smith JD, Jack MM, Harn NR, Bertsch JR, Arnold PM. Screw placement accuracy and outcomes following O-arm-navigated atlantoaxial fusion: a feasibility study. Global Spine J. 2016;6:344-9.

94. Elliott RE, Tanweer O, Boah A, Smith ML, Frempong-Boadu A. Comparison of safety and stability of $\mathrm{C}-2$ pars and pedicle screws for atlantoaxial fusion: meta-analysis and review of the literature. J Neurosurg Spine. 2012;17(6): 577-93.

95. Richter M, Cakir B, Schmidt R. Cervical pedicle screws: conventional versus computer-assisted placement of cannulated screws. Spine (Phila Pa 1976). 2005;30(20):2280-7.

\section{Publisher's Note}

Springer Nature remains neutral with regard to jurisdictional claims in published maps and institutional affiliations.

Ready to submit your research? Choose BMC and benefit from:

- fast, convenient online submission

- thorough peer review by experienced researchers in your field

- rapid publication on acceptance

- support for research data, including large and complex data types

- gold Open Access which fosters wider collaboration and increased citations

- maximum visibility for your research: over $100 \mathrm{M}$ website views per year

At BMC, research is always in progress.

Learn more biomedcentral.com/submissions 